\title{
Diverse gammacoronaviruses detected in wild birds from Madagascar
}

\author{
Francisco Esmaile de Sales Lima ${ }^{1} \cdot$ Patricia Gil $^{2,3} \cdot$ Miguel Pedrono $^{4,5} \cdot$ Cécile Minet $^{2,3}$. \\ Olivier Kwiatek ${ }^{2,3}$ - Fabrício Souza Campos ${ }^{1}$ - Fernando Rosado Spilki ${ }^{1}$. \\ Paulo Michel Roehe ${ }^{1}$ - Ana Cláudia Franco ${ }^{1}$ - Olivier Fridolin Maminiaina ${ }^{4}$. \\ Emmanuel Albina ${ }^{2,3,6}$ - Renata Servan de Almeida ${ }^{2,3}$
}

Received: 20 March 2015 /Revised: 12 May 2015 / Accepted: 14 May 2015 / Published online: 22 May 2015

(C) Springer-Verlag Berlin Heidelberg 2015

\begin{abstract}
To date, infectious bronchitis virus (IBV) is potentially found in wild birds of different species. This work reports the survey of coronaviruses in wild birds from Madagascar based on the targeting of a conserved genome sequence among different groups of CoVs. Phylogenetic analyses revealed the presence of gammacoronaviruses in different species of Gruiformes, Passeriformes, Ciconiiformes, Anseriformes, and Charadriiformes. Furthermore, some sequences were related to various IBV strains. Aquatic and migratory birds may play an important role in the maintenance and spread of coronaviruses in nature, highlighting their possible contribution in the emergence of new coronavirus diseases in wild and domestic birds.
\end{abstract}

Keywords Gammacoronavirus · Wild birds · Madagascar

Communicated by A. Aguirre

Francisco Esmaile de Sales Lima esmaile.sales@gmail.com

1 Virology Laboratory, Microbiology, Immunology and Parasitology Department, Institute of Basic Health Sciences, Federal University of Rio Grande do Sul (UFRGS), Porto Alegre, Brazil

2 CIRAD, UMR CMAEE, Montpellier, France

3 INRA, UMR1309 CMAEE, Montpellier, France

4 FOFIFA-DRZV, Antananarivo, Madagascar

5 CIRAD, UR AGIRS, Montpellier, France

6 CIRAD, UMR CMAEE, Petit-Bourg, Guadeloupe, France

\section{Introduction}

Coronaviruses (CoVs) are enveloped viruses within the Coronaviridae family with a positive-sense RNA genome ranging from 27 to $30 \mathrm{~kb}$ (Cavanagh 1997). They are divided into four genera: Alpha-, Beta-, Gamma- and Deltacoronavirus.

Alpha- and betacoronaviruses have been isolated from mammals; gammacoronaviruses, being the most representative member infectious bronchitis virus (IBV), have also been detected in the beluga whale (Mihindukulasuriya et al. 2008), the Asian leopard cat (Dong et al. 2007), and in several species of wild birds (Chu et al. 2011; Hughes et al. 2009; Jonassen et al. 2005; Muradrasoli et al. 2010; Woo et al. 2009). Viruses of the new proposed genus Deltacoronavirus were found primarily in mammals, terrestrial and aquatic birds (Chu et al. 2011; Dong et al. 2007; Woo et al. 2009).

In animals, $\mathrm{CoVs}$ are associated to respiratory and intestinal infections, as well as hepatic, renal, and neurological disorders (Cavanagh 2005). Human coronaviruses infections were generally related to the common cold, but the emergence and pandemic potential of severe acute respiratory syndrome (SARS) in 2003 and the Middle East respiratory syndrome (MERS) in 2012, both belonging to genus Betacoronavirus, led to the discovery of several CoVs hosted by humans and animals (Hilgenfeld and Peiris 2013).

Over the past years, the wildlife has been under epidemiological surveillance worldwide, as they can play an important role as reservoir of emerging viruses that may pose a risk to mankind and threaten wildlife itself. Wild birds are known to be important reservoirs of avian influenza A virus (Brown and Stallknecht 2008; Spackman 2009), as well as other respiratory and enteric viruses like IBV (Cavanagh and Gelb 2008). In poultry, the disease is controlled through the use of vaccines and biosafety measures, including avoidance of contact with 
wild birds. Upon vaccination, IBV generates antigenic variants that can result in incomplete protection (Cavanagh 2005).

Coronaviruses phylogenetically related to IBV were largely detected in several wild bird species in Northern England, as well as novel viruses that are not associated to classical IBV types (Hughes et al. 2009). This was also reported in the Beringian area between Alaska and Siberia (Muradrasoli et al. 2010) and in wild bird surveillance carried out in Hong Kong and Cambodia (Chu et al. 2011). These studies highlight the wide host range, geographic distribution, and diversity of avian CoVs, suggesting a possible impact on animal health and later a possible risk for human health (Muradrasoli et al. 2010).

In the present work, we report the detection and the phylogenetic aspects of coronaviruses detected in wild birds sampled at Alaotra Lake, Madagascar. This lake constitutes an exceptional site for the settlement of both endemic and migratory birds (BirdLife International 2014a). The sanitary and economic impacts of avian coronaviruses in the Madagascar poultry sector are still unknown.

\section{Material and methods}

For this work, we used part of the samples collected in the framework of the GRIPAVI project (http://gripavi.cirad.fr/ en/) launched in 2007, and concluded in 2011 by CIRAD in collaboration with the Département de Recherche Zootechnique et Vétérinaire du Centre National de la Recherche Appliquée au Développement Rural (FOFIFADRZV) in Madagascar, with the support of the French Ministry of Foreign Affairs. Cloacal swabs collected in 2011 from 357 free-ranging birds at Alaotra Lake on Madagascar highlands were used. The samples were dipped in a transport medium consisting of isotonic phosphate-buffered saline, $\mathrm{pH}$ 7.0-7.4, with antimicrobial additives (penicillin $10,000 \mathrm{U} / \mathrm{mL}$, streptomycin $10 \mathrm{mg} / \mathrm{mL}$, amphotericin B $25 \mu \mathrm{g} / \mathrm{mL}$, and gentamycin $250 \mu \mathrm{g} / \mathrm{mL}$ ) supplemented with $20 \%$ glycerol and stored in liquid nitrogen containers. They were shipped in dry ice and kept in the laboratory at $-80{ }^{\circ} \mathrm{C}$ until processing. All samples were manipulated in a biosafety level 3 laboratory.

Viral RNA was extracted from samples by a highthroughput-automated workstation Biomek FX ${ }^{\mathrm{P}}$ (Beckman Coulter) using the Nucleospin RNA virus kit, according to manufacturer's instructions (Macherey Nagel). The viral RNA was resuspended in nuclease-free water and stored at $-80{ }^{\circ} \mathrm{C}$. Moloney murine leukemia virus reverse transcriptase (Invitrogen) and random hexamers were used in $20 \mu \mathrm{L}$ reactions to generate cDNAs from $10 \mu \mathrm{L}$ of the extracted RNA suspension, according to the manufacturer's instructions.

The obtained cDNAs were submitted to a pancoronavirus nested PCR (nPCR) with Top Taq DNA polymerase (Qiagen), according to manufacturer's instructions. A segment of the RNA-dependent RNA polymerase (RdRp) was targeted with the following primers: CoV-F1 (5'-GGKTGGGAYTAYC CKAARTG-3'), CoV-R1 (5'-TGYTGTSWRCARAAYTCR TG-3'), CoV-F2 (5'-GGTTGGGACTATCCTAAGTGTGA$3^{\prime}$ ), and CoV-R2 (5'-CCATCATCAGATAGAATCATCATA$3^{\prime}$ ) (Chu et al. 2011). Briefly, the nPCR was performed as follows: the first reaction was performed in a $25-\mu \mathrm{L}$ volume containing $20 \mathrm{ng}$ of cDNA with primers $(\mathrm{CoV}-\mathrm{F} 1$ and $\mathrm{CoV}-$ R1). The cycling conditions were 5 min at $95^{\circ} \mathrm{C}, 40$ cycles of $45 \mathrm{~s}$ at $94^{\circ} \mathrm{C}, 40 \mathrm{~s}$ at $49^{\circ} \mathrm{C}, 45 \mathrm{~s}$ at $72^{\circ} \mathrm{C}$ and a final incubation at $72{ }^{\circ} \mathrm{C}$ for $7 \mathrm{~min}$. For the second (nested) reaction, we used $2 \mu \mathrm{L}$ of the first reaction under the same amplification conditions of the first PCR, but using primers $\mathrm{CoV}-\mathrm{F} 2$ and $\mathrm{CoV}-\mathrm{R} 2$ in the assay.

Standard precautions were taken to avoid PCR contamination; blank controls without template were included in every set of five RT-PCR assays. PCR products were electrophoresed in $1.5 \%$ agarose gels and the products visualized on UV light. The products with the expected size (400 to $440 \mathrm{bp}$ ) were excised and purified using QiaQuick gel extraction Kit (Qiagen) following manufacturer's instructions.

The positive samples were sequenced (Cogenics) with primers CoV-F2 and CoV-R2, using Big dye Terminator v3.1 (Applied Biosystems) cycle sequencing kit according to the manufacturer's instructions.

The BLAST was used to detect homologous regions in sequence databases. Sequences were aligned by ClustalW and MEGA version 6 (Tamura et al. 2013). Phylogenetic analysis was performed based on a fragment containing approximately $350 \mathrm{bp}$ of the RdRp CoV gene using the neighborjoining method with bootstrap support (1000 replicates) in MEGA version 6 (Tamura et al. 2013).

\section{Results and discussion}

Samples originating from 17 bird species were tested for CoVs polymerase RdRp gene by RT-PCR, and 28 of the 357 cloacal samples were positive $(7.8 \%)$. Positives were found in 11 species (Table 1). All sequences were submitted as GenBank:KM093872 to GenBank:KM093897; GenBank:KM093899 and GenBank:KM093901. Phylogenetic tree reconstructions enabled us to classify all the coronaviruses identified in this study as gammacoronaviruses (Fig. 1).

These gammacoronaviruses were detected in a wide broad of bird orders, such as the following: Gruiformes, Passeriformes, Ciconiiformes, Anseriformes, and Charadriiformes. Nucleotide distances between CoVs sequences in this study were $0.0-23.5 \%$. Sequences formed five different subgroups within two main clusters, revealing the diversity among avian CoVs strains from the same geographic 
Table 1 Detection of gammacoronaviruses in avian samples from Alaotra Lake, Madagascar

\begin{tabular}{|c|c|c|c|c|}
\hline Order & Species & Sampled $(n)$ & Positive $(n)$ & Rate $\%$ \\
\hline \multicolumn{5}{|c|}{ Anseriformes } \\
\hline & Anas erythrorhyncha & 82 & 4 & 4.9 \\
\hline & Dendrocygna bicolor & 21 & 0 & 0 \\
\hline & Anas melleri & 15 & 0 & 0 \\
\hline & Dendrocygna viduata & 40 & 3 & 7.5 \\
\hline & Anas hottentota & 54 & 1 & 1.8 \\
\hline \multicolumn{5}{|c|}{ Charadriiformes } \\
\hline & Gallinago macrodactyla & 18 & 3 & 16.6 \\
\hline & Charadrius pecuarius & 15 & 3 & 20 \\
\hline & Rostratula benghalensis & 4 & 1 & 25 \\
\hline \multicolumn{5}{|c|}{ Ciconiiformes } \\
\hline & Bubulcus ibis & 8 & 1 & 12.5 \\
\hline & Ardeola ralloides & 3 & 0 & 0 \\
\hline \multicolumn{5}{|c|}{ Cuculiformes } \\
\hline & Centropus toulou & 4 & 0 & 0 \\
\hline \multicolumn{5}{|c|}{ Gruiformes } \\
\hline & Gallinula chloropus & 32 & 3 & 9.4 \\
\hline & Porphyrula alleni & 37 & 5 & 13.5 \\
\hline & Rallus madagascariensis & 8 & 1 & 12.5 \\
\hline & Dryolimnas cuvieri & 2 & 0 & 0 \\
\hline \multicolumn{5}{|c|}{ Passeriformes } \\
\hline & Foudia madagascariensis & 11 & 3 & 27.2 \\
\hline \multicolumn{5}{|c|}{ Strigiformes } \\
\hline & Tito alba & 3 & 0 & 0 \\
\hline Total 7 & 17 & 357 & 28 & 7.8 \\
\hline
\end{tabular}

area. Seven sequences from dabbling and whistling ducks formed a separate and distinct subcluster with a within group distance of $0.4-2.1 \%$ and a mean distance between the subclusters of $9 \%$. Three sequences (KM093887 to KM093889) from waders and rail were found to be phylogenetically closer to various IBV strains. Notably, three sequences derived from weavers and one from small waterbird (KM093890 to KM093892 and KM093901) fell into a different cluster within other gammacoronaviruses related to geese in Russia (Muradrasoli et al. 2010) and a whistling duck in Cambodia (Chu et al. 2011). These sequences are up to $24.6 \%$ divergent on the nucleotide level in comparison to the sequences recovered and located in the other main cluster.

In the present study, gammacoronaviruses were detected in $7.8 \%$ of the examined wild bird samples. This prevalence is higher by a magnitude of four than the one found in the same birds for avian Paramyxovirus type 1 (Cappelle et al. 2014). Sequences recovered from dabbling and whistling ducks were closely related to sequences isolated from gulls in Russia (Muradrasoli et al. 2010), sharing up to $93 \%$ of similarity on the nucleotide level. The fact that some sequences were more closely related to IBV strains highlights the question on the original reservoirs of IBV, if domesticated or wild birds (Hughes et al. 2009). The majority of the sequences here detected were phylogenetically related to avian CoVs detected in rock sandpipers (Eroliaptilocnemis). These related sequences were reported in the Commander Island, Russian Federation (Muradrasoli et al. 2010), highlighting not only its potential of geographic distribution but the interspecies transmission, as such, very similar viruses can be detected in different avian species: ducks, plovers, herons, weavers, waders, small water birds, and painted snipes. Noteworthy, this study shows that the same species can host genetically diverse gammacoronaviruses.

It is remarkable the phylogenetic similarities among most of the sequences herein detected and others from Asia. The only possible explanation lies on the coastal migratory movement Africa-Madagascar. The direct route of migration of waterbirds to Madagascar is from the Wetlands in Eastern Africa (Dodman and Diagana 2006). Although it is hard to predict, it would be possible that many migratory species could have previous contact with migrating birds from Western/Central Siberia, Balkans, Black Sea, and Central Asia which use the East Africa flyways to reach wintering areas to rest along the river systems crossing the Arabian Peninsula and the Nile (BirdLife International 2014b).

Taken together, our results demonstrate that there is circulation of genetically divergent avian CoVs among different wild bird species at Alaotra Lake, Madagascar. This lake is the island's most important rice-growing region and a rich habitat for wildlife, including relatively many endemics, rare, and endangered species (Ferry et al. 2009).

Due to the environmental conditions that prevailed in this region, it is assumed that in the case of introduction of other avian viruses, like avian influenza $\mathrm{H} 5 \mathrm{~N} 1$, this area may facilitate virus spread and persistence (Guerrini et al. 2014). Considering our results on the detection of avian $\mathrm{CoVs}$ in the samples studied here, we might assume that these viruses are widespread among birds found in this environment. The detection of sequences related to gammacoronaviruses in this study area and in geographically distinct areas, such as Russia, Alaska, and Cambodia indeed indicates that CoVs are widespread among birds associated with water environments, raising questions on possible implications on wildlife and poultry production.

The number of samples analyzed in this study was limited to predict the real prevalence of gammacoronavirus in Madagascar, but our results emphasize the circulation of genetically diverse coronaviruses in apparently healthy populations of wild birds from different species. Additional genetic data on coronavirus surveillance in a wide number of individuals and species, as well as the complete genomic characterization of these wild bird coronaviruses are required to better understand their evolution, the relationship between these viruses and wild bird population, and the risk of transmission to poultry. 
Fig. 1 Phylogenetic relationship between the nucleotide sequences corresponding to a portion of $350 \mathrm{bp}$ of the Coronavirus gene (RNA-dependent RNA polymerase gene) amplified from wild birds at Alaotra Lake.

Coronavirus detected in wild bird species in this study are denoted by black diamonds and their corresponding GenBank accession numbers. Sequences from others coronaviruses were included for comparative purposes
- Rallus madascariensis CoV MAdagascar 2011 KM093896

- Rostratula benghalensis CoV Madagascar 2011 KM093882

- Porphyrulla alleni CoV Madagascar 2011 KM093894

- Porphyrulla alleni CoV Madagascar 2011 KM093893

- Gallinula chloropus CoV Madagascar 2011 KM093885

- Gallinula chloropus CoV Madagascar 2011 KM09388

99 Gallinago macrodactyla CoV MAdagascar 2011 KM093895

- Foudia madagascariensis CoV Madagascar 2011 KM093899

- Charadrius pecuarius CoV MAdagascar 2011 KM093884

- Charadrius pecuarius CoV Madagascar 2011 KM093883

- Charadrius pecuarius CoV Madagascar 2011 KM093879

- Anas hottentota CoV Madagascar 2011 KM093880

- Bubulcus ibis CoV Madagascar 2011 KM093897

GU396685(Rock sandpiper coronavirus CIR-665821)

99 $\mathrm{LU} 396675$ (Western sandpiper coronavirus KR-28)

JN788792(J0579/Anas crecca/091127)

- Foudia madagascariensis CoV Madagascar 2011 KM093886

66.JN788804(J0901/Anas clypeata/091217)

[ JN788824(J1300/Anas clypeata/091223)

76F437672(12WB52)

KF437670(12WB19)

86 KF437674(12WB55)

_ JN788864(J1616/Anas acuta/100112)

KC869939(duck/CH/R355/2012)

LJN788785(J0554/Anas clypeata/091127)

99.JN788780(J0109/Anas crecca/091106)

JN788781(J0121/Anas crecca/091106)

5 GU396673(Pintail coronavirus PBA-124)

GU396672(Pintail coronavirus PBA-37)

-KF437666(12WB180)

GU396669(Pintail coronavirus PBA-15)

GU396668(Pintail coronavirus PBA-10)

98 GU396671(Pintail coronavirus PBA-25)

JN788830(J1393/Anas acuta/091230)

95 GU396682(glaucous-winged gull/Russia)

100 GU396683(black-headed gull/Russia)

GU396679(black-headed gull/Russia)

GU396680(black-headed gull/Russia)

72 Anas erythrorhyncha CoV Madagascar 2011 KM093877

- Dendrocygna viduata CoV Madagascar 2011 KM093878

97 Anas erythrorhyncha CoV Madagascar 2011 KM093876

Anas erythrorhyncha CoV Madagascar 2011 KM093875

Anas erythrorhyncha CoV - Madagascar 2011 KM093874

Dendrocygna viduata CoV Madagascar 2011 KM093872

80 Dendrocygna viduata CoV Madagascar 2011 KM093873

FN811147(4/91) JF893452(YN)

100 GU393337(lowa 97)

99 GU393336(Holte)

99 Gallinula chloropus CoV Madagascar 2011 KM093887

82 Gallinago macrodactyla CoV Madagascar 2011 KM093888 - Gallinago macrodactyla CoV Madagascar 2011 KM093889

FN430415(NGA/A116E7/2006)

LFJ904715(Cal557 2003)

GU393334(Gray)

99 DQ834384(M41)

EU817497(H52)

— EU022526(TCoV-ATCC)

GQ504725(Mass41 Vaccine)

$\mathrm{FJ807652( \textrm {H } 1 2 0 )}$

97 JF828981(ck/CH/LDL/101212)

87 GU393332(Delaware72) EU714028(ZJ971)

GU396677(Brent goose coronavirus KR-69)

GU396678(Brent goose coronavirus KR-88)

L_JN788879(KH08-0852/Dendrocygna javanica/080506)

- Foudia madagascariensis CoV Madagascar 2011 KM093901 Cluster B

- Porphyrula alleni CoV Madagascar 2011 KM093890

100 - Porphyrula alleni CoV Madagascar 2011 KM093891

४ Porphyrula alleni CoV Madagascar 2011 KM093892 NC 004718(SARS-Tor2) 
Acknowledgments The samples used in this work were obtained in the framework of the GRIPAVI project funded by the French Ministry of Foreign Affairs (MAE) via the FSP project [GRIPAVI 2006-26]. The collection of samples was coordinated by Véronique Chevalier. FESL is also grateful for the scholarship granted by the Federal Agency for Support and Evaluation of Graduate Education of Brazil (CAPES) and Science Without Borders program.

\section{References}

BirdLife International (2014a) Important bird areas factsheet: Lake Alaotra. http://www.birdlife.org/datazone/sitefactsheet.php?id= 6567. Accessed 17 Dec 2014

BirdLife International (2014b) East Asia/East Africa flyway. http://www. birdlife.org/datazone/userfiles/file/sowb/flyways/6_East_Asia East_Africa_Factsheet.pdf. Accessed 17 Dec 2014

Brown JD, Stallknecht DE (2008) Wild bird surveillance for the avian influenza virus. In: Spackman E (ed) Methods in Molecular Biology, vol 436. Humana Press, Totowa, pp 85-97

Cappelle J, Caron A, Servan de Almeida R, Gil P, Pedrono M, Mundava J, Fofana B, Balança G, Dakouo M, Ould el Mamy AB, Abolnik C, Maminiaina OF, Cumming GS, de Visscher MN, Albina E, Chevalier V, Gaidet N (2014) Empirical analysis suggests continuous and homogeneous circulation of Newcastle disease virus in a wide range of wild bird species in Africa. Epidemiol Infect 4:1-12

Cavanagh D (1997) Nidovirales: a new order comprising Coronaviridae and Arteriviridae. Arch Virol 142:629-633

Cavanagh D (2005) Coronaviruses in poultry and other birds. Avian Pathol 34:439-448

Cavanagh D, Gelb J (2008) Infectious bronchitis. In: Saif YM (ed) Diseases of poultry. Wiley-Blackwell Publishing, Ames

Chu DK, Leung CY, Gilbert M, Joyner PH, Ng EM, Tse TM, Guan Y, Peiris JS, Poon LL (2011) Avian coronavirus in wild aquatic birds. J Virol 85:12815-12820

Dodman T, Diagana CH (2006) Conservation dilemmas for intra-African migratory waterbirds. In: Boere GC, Galbraith CA, Stroud DA (eds) Waterbirds around the world. The Stationery Office, Edinburgh, United Kingdom
Dong BQ, Liu W, Fan XH, Vijaykrishna D, Tang XC, Gao F, Li LF, Li GJ, Zhang JX, Yang LQ, Poon LL, Zhang SY, Peiris JS, Smith GJ, Chen H, Guan Y (2007) Detection of a novel and highly divergent coronavirus from Asian leopard cats and Chinese ferret badgers in Southern China. J Virol 81:6920-6926

Ferry L, Mietton M, Robison L, Erismann J (2009) Alaotra Lake (Madagascar) - past, present and future Le lac Alaotra à Madagascar-passé, présent et futur. Zeitschrift für Geomorphologie 53:299-318

Guerrini L, Paul MC, Leger L, Andriamanivo HR, Maminiaina OF, Jourdan M, Molia S, Rakotondravao R, Chevalier V (2014) Landscape attributes driving avian influenza virus circulation in the Lake Alaotra region of Madagascar. Geospat Health 8:445-453

Hilgenfeld R, Peiris M (2013) From SARS to MERS: 10 years of research on highly pathogenic human coronaviruses. Antiviral Res 100:286-295

Hughes LA, Savage C, Naylor C, Bennett M, Chantrey J, Jones R (2009) Genetically diverse coronaviruses in wild bird populations of northern England. Emerg Infect Dis 15:1091-1094

Jonassen CM, Kofstad T, Larsen IL, Lovland A, Handeland K, Follestad A, Lillehaug A (2005) Molecular identification and characterization of novel coronaviruses infecting graylag geese (Anser anser), feral pigeons (Columbia livia) and mallards (Anas platyrhynchos). J Gen Virol 86:1597-1607

Mihindukulasuriya KA, Wu G, St Leger J, Nordhausen RW, Wang D (2008) Identification of a novel coronavirus from a beluga whale by using a panviral microarray. J Virol 82:5084-5088

Muradrasoli S, Bálint A, Wahlgren J, Waldenström J, Belák S, Blomberg J, Olsen B (2010) Prevalence and phylogeny of coronaviruses in wild birds from the Bering Strait area (Beringia). PLoS One 5:e13640

Spackman E (2009) The ecology of avian influenza virus in wild birds: what does this mean for poultry? Poult Sci 88:847-850

Tamura K, Stecher G, Peterson D, Filipski A, Kumar S (2013) MEGA6: molecular evolutionary genetics analysis version 6.0. Mol Biol Evol 30:2725-2729

Woo PC, Lau SK, Lam CS, Lai KK, Huang Y, Lee P, Luk GS, Dyrting KC, Chan KH, Yuen KY (2009) Comparative analysis of complete genome sequences of three avian coronaviruses reveals a novel group 3c coronavirus. J Virol 83:908-917 